Larrahondo, B.F. (2016). La carrera del paciente mental: un estudio de tres familias. Revista de Sociología y Antropología: VIRAJES, 18 (1), 263-287. DOI: 10.17151/rasv.2016.18.1.12

\title{
LA CARRERA DEL PACIENTE MENTAL: UN ESTUDIO DE TRES FAMILIAS*
}

\section{BRAYAN FERNANDO LARRAHONDO**}

Recibido: 14 de septiembre de 2015

Aprobado: 28 de marzo de 2016

Artículo de investigación

\footnotetext{
* Este artículo recoge los aportes más significativos de la monografía Larrahondo Erazo, B. F. (2014). La carrera del paciente mental: un estudio de tres familias del municipio de Candelaria realizada en el Programa Académico de Sociología de la Universidad del Valle durante los años 2013-2014.

** Sociólogo, Universidad del Valle. Correo electrónico: brayan.larrahondo@correounivalle.edu.co (1) ORCID: 0000-0002-4979-6199
} 


\title{
Resumen
}

Este trabajo describe mediante categorías sociológicas las etapas de la carrera del paciente mental. La información proporcionada por los familiares de tres personas que padecen de esquizofrenia en el municipio de Candelaria(Valle del Cauca) ha servido para analizar la manera como se organiza el proceso de construcción del paciente mental. El relato familiar de la enfermedad mental habla de la biografía, de la personalidad del paciente mental, intenta establecer las causas y describe con minuciosidad los síntomas, los signos, además de las transgresiones cometidas por las personas que padecen de esquizofrenia.

Palabras clave: familia, enfermedad mental, carrera, paciente mental, síntomas, transgresiones.

\section{MENTAL PATIENT CAREER: A STUDY OF THREE FAMILIES}

\begin{abstract}
This paper describes the stages by sociological categories of mental patient's career. The information provided by relatives of three people with schizophrenia in the town of Candelaria (Valle del Cauca) has been used to analyze how the process of building the mental patient is organized. The familiar story of mental illness talks about the biography, personality, mental patient, trying to establish the causes and describes in detail the symptoms, signs besides the transgressions committed by people with schizophrenia.
\end{abstract}

Key words: family, mental illness, career, mental patient, symptoms, transgressions. 


\section{INTRODUCCIÓN}

lgunas personas se internan en hospitales psiquiátricos por
voluntad propia, bajo el consentimiento de su familia o
cuando perciben en sí mismos signos de locura tales como escuchar voces, sentirse perseguidos o estados agudos de irascibilidad, etc. Otras veces los individuos son internados en contra de su voluntad, ya sea por la presión de su propia familia o de la comunidad, y en los peores casos, con el uso de la fuerza.

Convertirse en paciente mental puede ser entendido como un proceso de carrera social. Pensamos que lo relevante para el conocimiento sociológico de la enfermedad mental no es explicar la naturaleza del sufrimiento mental de los individuos en sociedad, sino dar cuenta del hecho social de que existen personas que son definidas y tratadas por la sociedad como enfermos mentales. Esto resulta significativo cuando a través del análisis del discurso familiar advertimos los mecanismos sociales que actúan en la carrera de un paciente mental.

El presente artículo recoge los resultados más importantes derivados de una investigación principalmente cualitativa, apoyada en el análisis documental, la visita a hogares y las entrevistas a familiares de personas diagnosticadas con esquizofrenia. Se trata de exponer al lector los procesos, situaciones, interacciones y subjetividades que se presentan a lo largo de las etapas de la carrera del paciente mental. Desde este punto de vista, es importante mostrar cómo la definición de enfermedad mental y la hospitalización psiquiátrica obedecen, en sus justas proporciones, a los marcos de referencia de significación en los individuos que hacen parte de las redes sociales del paciente mental.

\section{ESTRATEGIA DE INVESTIGACIÓN}

Debido a que enfermedad mental es un concepto muy amplio que se refiere principalmente a todos aquellos trastornos que hoy conforman el amplio campo de acción e investigación de la psiquiatría, es decir, todos aquellos trastornos queen la actualidad tienen una vigencia efectiva (Ruiloba, 2003); se optó por estudiar sólo los casos de personas con esquizofrenia ya que es el trastorno mental que más se relaciona y ajusta con la idea social e histórica de "locura". En consecuencia, esta aproximación no tiene en cuenta a las familias de personas con diagnósticos de discapacidad mental (síndrome de Down, autismo) y patologías orgánicas-cerebrales (mal de 
Alzheimer).También quedan por fuera los casos de pacientes ambulatorios que a pesar de estar diagnosticad os con esquizofrenia, recibir farmacoterapia y acudir a consultorios médicos, nunca han sido hospitalizados.

Hay que resaltar la dificultad de conseguir la participación de un número mayor de familias para el estudio, la razón más frecuente de la negativa era que los parientes de los pacientes mentales consideraban la enfermedad mental de sus seres queridos como asuntos muy privados y dolorosos. Así las cosas, en la investigación participaron tres familias residentes en el municipio de Candelaria ${ }^{1}$ que cuidaban cada una de un pariente con esquizofrenia. Se requirió que el pariente en cuestión estuviera diagnosticado a través de criterios estrictamente médicos, con esquizofrenia en cualquiera de sus variaciones. De igual manera, se demandó que esta persona tuviera una edad superior a los 18 años y que hubiese sido hospitalizada por lo menos una vez en su vida en cualquiera de las unidades de salud mental de las instituciones psiquiátricas del Valle del Cauca. Todos estuvieron hospitalizados en distintas épocas en el Hospital Departamental Psiquiátrico Universitario del Valle.

Se advierte al lector que este trabajo no incluye a familias de mujeres con esquizofrenia, por dos razones: en primer lugar, porque si bien la esquizofrenia no es una enfermedad exclusiva del sexo masculino, estadísticamente es un síndrome más común en hombres que mujeres (Usall J., 2003, pp. 276-87); y en segundo lugar, porque todas las familias consultadas de mujeres que tenían algún tipo de enfermedad mental, como trastorno bipolar, se negaron a participar de la investigación.

En lo que refiere a la información empírica se trabajó con una fuente documental compuesta por los documentos que componen las historias clínicas de pacientes mentales, informes de medicina laboral y material fotográfico dispuesto por las familias. Otra parte de la información provino de las entrevistas realizadas a los parientes más cercanos de cada paciente mental, con los cuales se empleó un tipo de entrevista en profundidad encaminada a privilegiar las descripciones y los relatos sobre la vida de sus parientes con esquizofrenia. Sin embargo, es importante aclarar que los discursos obtenidos no son producto de la convivencia cotidiana del investigador en el entorno familiar de los informantes, sino consecuencia de la aplicación de entrevistas semi-estructuradas en "situaciones conversacionales" y escenarios pactados con los entrevistados.

La recolección, el análisis de los documentos y las entrevistas se

\footnotetext{
${ }^{1}$ Candelaria es un municipio ubicado en el sur del Valle del Cauca cuya actividad económica es principalmente la agroindustria, cuenta con una población de cerca de 67.044 hab. Para el año 2010, la Secretaria de Salud del Valle informó que el $18.2 \%$ de los casos de trastornos mentales reportados en el municipio correspondieron a esquizofrenia y trastornos delirantes (RIPS, 2010).
} 
hicieron durante el segundo semestre del 2013. Por razones éticas se han sustituido los nombres reales de las familias y de los pacientes. El "familiar curador" del paciente mental, es decir, el pariente sobre el cual recae la responsabilidad de representar los intereses del paciente mental en cuestiones jurídicas y civiles, gestionó el consentimiento del paciente mental para la manipulación y el estudio de los documentos privados, laborales e historias clínicas.

Parte de la información recolectada no se ha publicado ni en la monografía ni en este artículo por petición de la familia y del propio paciente mental. En todo caso, el lector puede tener la certeza de que la información omitida no es indispensable para comprender el argumento de la aproximación aquí expuesta. La dificultad para encontrar familias dispuestas a participar de la investigación y el correcto manejo de la información privada de las personas son muestra de las dificultades enfrentadas al llevar a cabo investigaciones relacionadas con el tema de la enfermedad y la salud mental.

\section{LA CARRERA DEL PACIENTE MENTAL}

"Las desviaciones se dejan estudiar como las carreras laborales; encadenamientos de etapas que transportan al actor a lugares sociales diferentes modificando también su estado subjetivo, sus intereses, sus perspectivas, sus oportunidades." (Moreno p., 1999: 65-66)

La investigación buscó operar y contrastar empíricamente las categorías de análisis establecidas en la teoría sustantiva de Erving Goffman (2001) sobre el tema de la situación social de los enfermos mentales. A través de las nociones de "paciente mental", "circuito de agentes" y "carrera de paciente mental", entre otras, se establece un lente de análisis sociológico por el cual se examinan los discursos y relatos concernientes a las percepciones familiares sobre la enfermedad mental.

Según E. Goffman (2001), un paciente mental es toda persona que ha sido internada en un servicio hospitalario de psiquiatría o unidades de salud mental de instituciones médicas. Más que la enfermedad en sí misma, es la experiencia de hospitalización la que constituye una afectación importante del destino social del individuo.

Así pues, para E. Goffman la noción de "carrera" equivale a "la trayectoria social recorrida por cualquier persona en el curso de su vida" (2001,p. 133). De acuerdo con esta idea, lo que interesa a la sociología son las trayectorias sociales de los individuos que se encuentran agregados dentro de una categoría social en los términos de sus propios procesos 
sociales. En este caso, la de los individuos agregados dentro de la categoría de pacientes mentales. El concepto de "carrera" así visto abarca tanto los aspectos subjetivos de la experiencia particular de los actores como aquellos elementos formales e institucionales de la trayectoria social del paciente mental (Goffman, 2001, p. 133). La ventaja de este modelo de análisis es que permite al investigador oscilar entre asuntos subjetivos muy personales $\mathrm{y}$ aquellos asuntos que conciernen a la esfera de lo público, logrando evitar que el problema de la construcción del paciente mental se limite a sólo lo que "una persona dice pensar que imagina ser" (Goffman, 2001, p. 134).

El concepto de "carrera" del paciente mental (no sólo sus aspectos morales) se interesa por la secuencia de cambios que se introducen en la vida de las personas que padecen alguna forma sufrimiento psíquico y afina la distinción entre los efectos resultantes de ser tratado como un enfermo mental y aquellos efectos que se producen sobre la vida de las personas a causa de los rasgos considerados propiamente psicopatológicos.

De hecho, la "carrera del paciente mental" obedece a un modelo secuencial ya que todas las causas que influyen en la enfermedad mental no actúan al mismo tiempo. Se habla de un continuo de experiencias que los pacientes mentales transitan, una agenda común, previsible y ordenada, compuesta por los momentos significativos de su trayectoria social(Moreno. J.L, 1999, p. 65).

A medida que se progresa en el curso normal de la enfermedad y conforme se exteriorizan e instalan en la persona síntomas mórbidos, emergen modificaciones al espacio social y las relaciones sociales del individuo, tan importantes para su destino como el curso natural de la enfermedad misma. Como resultado se dan profundas transformaciones en la identidad social de la persona: el cuestionamiento público sobre el buen juicio, la salud mental y la imagen pública; las alteraciones y rupturas del proyecto personal; la alteración del rol; la intervención forzada de circuitos de agentes y agencias; los procesos de internación; los cambios en las situaciones de convivencia familiar; los cambios en el estatus y las libertades civiles y el etiquetamiento; todos estos son procesos encadenados y comunes entre quienes padecen algún tipo de enfermedad mental como la esquizofrenia.

Repetimos, el estudio de la "carrera del paciente mental" no se inmiscuye en debates etiológicos. Lo dicho hasta aquí supone la idea de que paralelamente a la manifestación de rasgos de morbilidad, la persona que padece una enfermedad mental y que se ve inmersa dentro de los servicios hospitalarios para enfermos mentales debe afrontar ajustes sociales en su vida que además son comunes entre quienes comparten su misma suerte. Se debe insistir más bien en la idea de Goffman (2001) de que aquellos 
individuos que la sociedad ha definido como enfermos mentales comparten "circunstancias significativamente similares, a las que responden de manera similares", continúa: "no como consecuencia de su situación mórbida sino a pesar de ella"(2001, p.135).

Para la sociología, la naturaleza epistemológica del diagnóstico, la evolución clínica particular de cada condición patológica o la prognosis no son de ninguna forma los referentes a partir de los cuales se puede estructurar la "carrera del paciente mental". Más que de la enfermedad, la "carrera" y por ende la construcción del paciente mental depende de las fases en las que un agregado de individuos considerados "insanos" adquieren un destino social común al que deben someterse en el marco de una intervención terapéutica y social por parte de otros, en contraposición, "sanos".

Cualquier persona es susceptible de convertirse en paciente mental y existe una gran diversidad entre los distintos casos que lo hicieron. Independientemente de la psicopatología que se experimente, la reelaboración social de una persona como paciente mental (en su sentido sociológico) se da a causa de la alteración de su destino social, que se hace patente con la hospitalización. Así pues, la "carrera del paciente mental" en términos sociales se constituye de tres etapas sucesivas:l a etapa pre-paciente, la primera, que equivale al tiempo previo a la primera hospitalización. En segundo lugar tenemos la etapa de paciente que corresponde al periodo de tiempo que la persona es internada en los servicios hospitalarios de psiquiatría; y por último, la etapa de ex-paciente o etapa recidiva que es el periodo posterior al alta de la hospitalización, durante el cual la persona puede o no presentar reingresos.

Hay que recalcar que cada fase por la que pasa la persona en su camino hacia su re-elaboración personal como paciente mental, modifica la disposición de los actores y la percepción de la situación del individuo enajenado. Por lo tanto, los discursos de las redes sociales del paciente mental varían en función de la distancia social y el contexto desde el cual se observe la desviación.

\section{ETAPA PRE-PACIENTE}

La fase pre-paciente es el primer estadio de la "carrera del paciente mental" e inicia formalmente cuando un agente "denunciante" entabla la acción que vista de forma retrospectiva es la que efectivamente causa el internamiento de una persona, lo que indicaría que la "carrera" del paciente mental tiene un comienzo social. Sin embargo, para este límite 
inicial se debe sugerir una idea sobre la cual la presente investigación arrojó otra perspectiva. El hecho de que actualmente la acción denunciante por sí sola es insuficiente para determinar la hospitalización de una persona, hace inapropiado fijar un límite inicial de la carrera con respecto al acto de denuncia. Además, es claro que se necesita de un proceso de medicalización complejo, que determine de forma rigurosa, que las características de la conducta del individuo sospechoso de estar perdiendo la razón se adecuan a las de un verdadero caso psiquiátrico.

La reconstrucción psiquiátrica de la vida de la persona por parte de los expertos implica que el inicio de la carrera podría situarse en momentos anteriores a la denuncia y que además requiere del consentimiento y la intervención de otras agencias como las "mediadoras". Es posible rastrear el inicio psicopatológico de la enfermedad mental y sus consecuencias sociales desde momentos muy tempranos en la vida de las personas. La aparición de los primeros signos y síntomas son un buen referente para ubicar el inicio de la "carrera del paciente mental" (Tizón J. \& otros, 2004, pp. 493-498). Existen casos en los que estas señales prematuras de la enfermedad pasan desapercibidos y otros en los que los familiares sospechaban de la salud mental de su ser querido desde cuando este era muy joven, aun cuando estos supuestos indicios de enfermedad solo fueran rasgos normales de una personalidad descentrada.

No era de las personas normales como... que saliera que tuviera cantidad de amigos, que fuera una de las personas que dijera: "No me voy para el parque, me voy con mis amigos" tuviera una novia, se viera como otras personas que dicen: "Voy a tener un hogar, voy a tener mis hijos", nunca se le vio, nunca se le escuchó hablar de un sueño.

Gertrudis L., 42 años. Hermana

Mi tía nos contaba que la primera vez que ella lo vio mal, fue un día que ella salía de la universidad, que él salió de la universidad. Y fue porque mi tía vivía en Prados del Norte, ¡vive cerca de la academia! entonces él se iba hasta donde mi tía y que cuando ella llegó, ella lo vio sentado en las escaleras de la casa y que él miraba hacia arriba y que le decía que él veía cosas en el cielo. Él le decía tía mira, pero se reía. Claro mi tía fue la primera que se dio cuenta...

Gloria V., 23 años. Hermana

Durante este periodo y lo que dura la sospecha, son muchos los inconvenientes que una persona puede causarse a sí mismo o a sus relaciones sociales antes de que ella o la familia piense su conducta en términos 
de enfermedad mental. Un aspecto importante es que la enfermedad mental puede estar acompañada de otros procesos de desviación social (drogadicción, homosexualidad, criminalidad), que se dan de forma paralela a los procesos de morbilidad o que según la familia, actúan como detonadores de la enfermedad.

Es que al principio no entendían, por decirte a él lo llevaban, que a... ¿Cómo se llaman esas casas a donde llevan a las personas que consumen? - ¿Reposo? ¿Rehabilitación?-. Eso, que por la droga... Cuando ya, eso no era normal las reacciones de él, ya lo comenzaron fue a internar en el psiquiátrico.

Gloria V., 23 años. Hermana.

La experimentación de los síntomas y signos de deterioro mental son una experiencia definitiva en la vida de las personas porque afecta la identidad y la capacidad de interactuar con otras personas. La aparición de comportamientos irascibles supone dudas para los demás sobre la probidad de la persona, dudas de que este sea un ciudadano digno de ser tratado con diligencia. El individuo que se encuentra frente a la penosa posibilidad de estar enloqueciendo puede intentar ocultar lo más que pueda su desarreglo a los demás y tratar de disimular los hechos de locura (puede que solo él los perciba así).

Los casos más graves y extravagantes en esta etapa de la carrera son aquellos en los que pareciera que la persona ignorara por completo los apuros que su comportamiento ocasiona al medio social, sobre todo a su familia. Esta situación aporta tensión, es un periodo en que se producen los antecedentes necesarios para que el "agente denunciante" cumpla con su rol. Solo es cuestión de tiempo hasta cuando el pre-paciente cometa las más graves transgresiones que le significarán la hospitalización y un punto de no retorno hacia su vida social pasada.

Él no se dio cuenta, porque como él vivía con mi mamá, cuando ya nosotros nos dimos cuenta ya él estaba muy mal, ni mi mamá ni él se dieron cuenta de lo que estaba pasando. Cuando ya mi mamá me dijo a mí, ya fue porque él estaba en una crisis muy tremenda. Ya cuando una crisis muy grave fue cuando mi mamá vino corriendo y me dijo: ve pasa esto y esto; ahí fue cuando yo me puse pilas y fui a buscar ayuda y busque. Lo llevamos donde el médico, luego lo llevaron a San Isidro, incluso eso fue con policía y todo.

Gertrudis L., 42 años. Hermana. 
Podríamos argumentar que el inicio de la "carrera del paciente mental", es decir el tiempo en la biografía en un individuo donde comienza su trayectoria como enfermo mental tiene dos características fundamentales. Por un lado, la presencia de "contingencias de carrera" que las podríamos precisar como los elementos situacionales que determinan que la persona quede sujeta en los servicios hospitalarios para enfermos mentales y no en otros lugares o destinos. Las contingencias de carrera son útiles para diferenciar a aquellos que cometen un acto desviado y no reciben una sanción institucional de aquellos que sí la reciben.

Podríamos impugnar que son los aspectos circunstanciales de la vida social los que cuentan para la internación. Circunstancias como la capacidad económica del paciente y su familia, la representación social de la enfermedad mental, la notoriedad o gravedad de la transgresión, incluso la opinión de la comunidad sobre el tipo de tratamiento y el servicio que brindan en los hospitales psiquiátricos, son los elementos situacionales que dinamizan la internación de una persona y su eventual salida.

Aun con todo lo dicho esta concepción de la hospitalización psiquiátrica tiene sus matices evidentes, puesto que hoy más que antes en las unidades psiquiátricas existen medidas terapéuticas encaminadas a evitar en lo posible la hospitalización de personas. Este cambio parece obedecer en gran medida por la reflexión académica dentro de la misma disciplina psiquiátrica y además por cuestiones administrativas como los costos económicos de la hospitalización y escasez de especialistas. Sirva de ejemplo que el hecho de tener antecedentes familiares de algún tipo de enfermedad mental, constituye una de las contingencias de carrera vistas más influyentes a la hora de determinar el camino a seguir por la familia y los expertos.

No era de las personas que... con las cuales uno podía entablar una conversación coherente y porque ya había antecedentes de mi otro hermano y yo sabía que de pronto podía pasarle a él también porque él mantenía muy solo.

Gertrudis L., 42 años. Hermana.

Llegados a este punto hay que hacer énfasis en la falta de homogeneidad entre las contingencias de carrera de un individuo a otro. La variedad de circunstancias las hace imposibles de categorizar bajo una naturaleza común. Incluso, la gravedad de las transgresiones cometidas por el pre-paciente depende de la distancia social desde la cual se juzga la situación (Goffman, 2001:135). 
Nota diario de Campo, 21 de mayo, 2013.

“Dice que el paciente durante algunos exámenes médicos de urgencia, "simulaba" y decía encontrarse bien y no necesitar ayuda médica, a lo que los médicos responden con simpatía y dando poca importancia a los episodios de ira y a los hechos ocurridos en el hogar que remite su familiar. Sin embargo, salvo estos episodios, la conducta de Julio (dice su sobrina) parece ser tímida, le gusta conversar y goza de conciencia sobre su enfermedad".

La contingencia de carrera depende entonces de cada situación y posición social, así que por muy similares que sean las transgresiones cometidas por alguien, en un contexto determinado, estas pueden acarrear derivaciones de distinto orden para otra persona. Hay quien habiendo transgredido el orden social, por causa de una posible enfermedad mental, se le envía a la cárcel, al exilio o su situación termina en un divorcio. Tampoco se quiere decir que la hospitalización depende del azar o que sea fortuita. Antes de que un familiar piense que su ser querido está padeciendo una enfermedad mental (en la mayoría de pacientes) es posible hacer un recuento largo y denso de transgresiones que este cometió. Los hechos acumulados conducen a la hipótesis de la enfermedad mental, la cual resulta efectiva en la medida en que proporciona continuidad y explicación. Luego, el desencadenamiento puede ser distinto para cada persona, tenemos casos en que las transgresiones de un pre-paciente tienen como consecuencia, primero la ruptura de su relación familiar y el divorcio antes que la hospitalización.

Cuando ellos eran novios y ella quedó embarazada, él no reaccionaba así. O sea, él era normal, trabajaba y todo. Como te lo explico, ellos fueron novios, ella quedó embarazada, tuvo a la niña, a él le comenzaron a dar las crisis y ellos se separaron. Por las crisis.

Gloria V., 23 años. Hermana.

Una segunda característica importante del inicio de la carrera del paciente mental es la presencia e interacción de los "circuitos de agentes y agencias". El primero de estos, compuesto por la persona más allegada, quien a menudo es un familiar. En segundo lugar está el circuito del agente o agencia denunciante y en el tercer circuito se encuentran las agencias mediadoras. Los circuitos son agentes de rol y por ello una misma persona o agencia puede desempeñar más de un rol al tiempo. Estas personas interactúan con el paciente, frecuentan sus espacios e intervienen en la transición de su estatus civil al estatus de paciente mental. Cuando el 
paciente llegue a ser hospitalizado, habrá hecho concesiones y se habrá relacionado con casi todos los circuitos.

En el "circuito allegado" se encontrarán la familia de orientación, la de procreación y tal vez los amigos cercanos y es el círculo que mantiene la relación más íntima con el pre-paciente. Son quienes tienen la mayor información sobre la situación y la biografía del pre-paciente y por lo tanto deberán relacionarse y entenderse con las "agencias mediadoras", las cuales les transmiten sus conceptos, recomendaciones y decisiones cuando fuere necesario. La confianza es uno de los aspectos esenciales en la relación entre este primer circuito y el paciente mental, como vemos en algunos casos se delega este rol a quien el paciente aprecie suficiente, con quien se sienta seguro de que sería incapaz de actuar en contra de su interés. "Mi tía, era a quien más quería, ella estaba encargada de todas las cosas de él, ella ya falleció" (Gloria V., 23 años. Hermana).

La "agencia denunciante", por su parte, puede tratarse de un familiar, un compañero de trabajo o alguien totalmente ajeno al pre-paciente como un funcionario público, un policía o la víctima de alguna transgresión del pre-paciente. Retrospectivamente, es el responsable de haber puesto a la persona en el hospital de enfermos mentales, o por lo menos de pedir la intervención de autoridades y poner en duda la salud mental de una persona.

A él lo hospitalizaron en San Rafael la primera vez gracias unos amigos de él, porque cuando se enfermó estaba viviendo solo en Pasto. Los amigos fueron los que lo llevaron al médico cuando vieron que él se puso malo.

Rosario D., 48 años. Sobrina.

Cada que habían peleas mi papá tenía que ir a la casa de ellas y todo eso. Porque él vivía con la esposa en la casa de la mamá de él. Entonces siempre que había eso, ehh... -¿Llamaban a tu casa?-. Ajá. A mi papá. Entonces hubo en momento en que él ya se salió de control y pues a él lo tuvieron que internar. Él estuvo en el psiquiátrico.

Gloria V., 23 años. Hermana.

En cuanto a los "circuitos mediadores", estos son una sucesión de profesionales y autoridades a los que se transfiere la suerte del paciente mental durante su "carrera". El circuito está compuesto por policías, clérigos, médicos generalistas, trabajadores sociales, directores de hospital, directores de asilos, juntas médicas, psiquiatras y hasta abogados. Una de estas agencias tendrá el mandato legal que permite la hospitalización voluntaria o no de una persona. Luego que la persona es diagnosticada y 
durante lo que dure la hospitalización, la única agencia mediadora que se mantiene es la dirección de la unidad psiquiátrica encarnada en un director o un jefe especialista de la unidad en que el paciente se encuentre. Un rasgo importante y definitorio de este grupo es que en todos los casos las agencias mediadoras mantienen una relación estrictamente profesional con el paciente.

Los agentes y agencias mediadoras tienen un mayor manejo del conocimiento clínico y psiquiátrico. Basados en el carácter racionalista de sus funciones profesionales, optan por creer y recomendar la conveniencia de la hospitalización y el manejo clínico para aquellos individuos sobre los cuales pesa un diagnóstico de enfermedad mental y que dadas las condiciones resultan no aptos para el tratamiento ambulatorio.

La confianza en la capacidad terapéutica del tratamiento brindado dentro de los centros hospitalarios, hacen de los "circuitos mediadores" difusores de la extendida idea de que este es el lugar más apropiado para la persona y que es la solución más eficiente a los problemas causados. La confianza y aceptación de medios ofrecidos como racionales ayuda a alivianar la responsabilidad de la familia, hace soportable el hecho de haber actuado en contra de la voluntad de su ser querido. Además, el discurso experto proporcionado por las "agencias mediadoras" a las familias, ofrece continuidad y previsibilidad al proceso, a la carrera, aun cuando esta resulte desagradable para los implicados en muchos aspectos.

En algunas ocasiones, en la vida posterior a la hospitalización las "agencias mediadoras" siguen ejerciendo su rol como puente entre la vida personal del paciente y la formalidad institucional de su situación, así como también continuarán comunicándose con los "circuitos allegados" de los pacientes. Esta comunicación es muy importante porque permite que las transiciones del paciente mental se den en orden y abiertamente. Son representantes que la sociedad ha proporcionado para regular aspectos relacionados con el destino social, los derechos y libertades del paciente mental.

A continuación mostramos un aparte del Certificado de Calificación de Invalidez de un paciente mental elaborado por una junta regional de calificación, en el que se decreta la pérdida de capacidad laboral de la persona y el requerimiento de un curador:

“CERTIFICA: Que la junta de calificación de invalidez en sesión llevada a cabo el día 19 del mes de NOVIEMBRE del año dos mil cuatro 2004 y mediante acta No. 050-2004 de la misma fecha, se procedió a calificar al señor(a) LEONEL LOZANO identificado con la cédula de ciudadanía No. X.XXX.XXX de CANDELARIA constando 
en el acta que establecidos los fundamentos de hecho y derecho, los criterios de evaluación de acuerdo al manual Único para la Calificación de Invalidez(Decreto 197 de 1999 y 2463 de Noviembre 20/01), por unanimidad manifestaron que en su concepto la pérdida de Capacidad Laboral es la siguiente: FECHA DE ESTRUCTURACION P.C.L. 12/11/2003. - REQUIERE CURADOR-.

Deficiencia: 30\%. Discapacidad: 3\%. Minusvalía: 23\%. Total: 56\%.

Determinación de Origen: COMÚN

Diagnóstico. ESQUIZOFRENIA INDIFERENCIADA CRÓNICA"²

El pre-paciente en su inicio cuenta con todos los derechos, libertades y satisfacciones que se esperan en la vida civil de un adulto libre; para cuando se convierte en paciente muchos de estos beneficios estarán limitados o regulados. Incluso la vida cotidiana se trastoca. Las "agencias mediadoras" no tratan estos temas directamente, si no son su competencia y cuando los son, para evitar desazones con el afectado, prefieren hacerlo con un "agente allegado" que represente los intereses del paciente.

Las agencias mediadoras tienden a requerir del "circuito allegado", una figura tutelar de "curador", es decir, un responsable ante la sociedad de los asuntos más trascendentales del paciente mental. La intimidad y confianza existente entre el paciente mental y su circuito allegado garantiza que la transición sea ordenada, y si el paciente está de acuerdo con la persona elegida como curador, difícilmente se podrá elegir a otra.

Estar pendiente de él, en cuestión de economía el recibe su pensión porque más que todo se nombró porque le metimos pleito por la pensión y estar pendiente de él más que todo, él no puede firmar ya nada legal... O sea, cuando empezamos los trámites de la pensión de todo eso tuvieron que nombrarme tutora, curadora. Eso se hace por medios legales, un juez lo pide. Entonces nos tocó ir donde un médico, no me acuerdo como se llama el médico y él fue el que, o sea, ellos tomaron la decisión de que era yo, y luego me tocó que ir donde un médico, el médico lo vio y el médico habló con él y todo, con mi mamá, Olga y todos, entonces ellos tuvieron que firmar papeles para yo poder ser la curadora...Si eso tiene un nombre especial, no me acuerdo como se llama ese médico pero hay que ir donde él y luego esos papeles van otra vez donde los jueces y luego ya está un tiempo allá y pasa el proceso y luego ya dan el veredicto. Gertrudis L., 42 años. Hermana.

\footnotetext{
${ }^{2}$ E. O. Quiñones. Secretaría Técnica. “Calificación de Invalidez". Junta regional de calificación de invalidez del Valle del Cauca. Ministerio de la Protección Social. República de Colombia. Acta No. 050-2004. (Los resaltados son del documento).
} 
En este proceso de expropiación y ajustes de libertades existe por supuesto una amplia interacción entre los distintos circuitos, los procesos son interdependientes. Por ejemplo, la participación del circuito mediador otorga legitimidad a las medidas que son solicitadas ya sea por las agencias "denunciantes" o "allegadas", esta comunicación es imprescindible cuando en los primeros momentos de la carrera se hace necesario actuar en contra de la voluntad del pre-paciente.

Sí, yo hablé con el doctor Orjuela, el doctor Orjuela no lo vio pero yo le dije los síntomas. Yo fui y le comenté, él me dijo que lo llevara, entonces le dije él no quiere venir, nosotros no somos capaces de traerlo. Entonces él me dijo; "Yo voy a hacer algo; yo te voy a dar una remisión y tú lo llevas a San Isidro, porque los síntomas que él tiene creo y si no estoy mal es esquizofrenia", porque él escuchaba voces, y decía que nosotros él fue a la policía y les dijo que a mí me tenían secuestrada y que él sabía quién me había secuestrado, y dijo que Aura me había secuestrado y la policía le creyó y fue con él hasta donde Aura. Y él también decía que nosotros íbamos a vender la casa y que lo íbamos a dejar a él y mi mamá en la calle. Gertrudis L., 42 años. Hermana.

La consecuente hospitalización a la que conduce la etapa pre-paciente contiene varios significados, todo depende del rol que se desempeñe y la distancia social desde la cual se observe el proceso. Para el ahora paciente puede constituir un verdadero acto de ingratitud y confinamiento por parte de sus familiares y amigos, mientras que para el circuito "mediador" la hospitalización es la forma idónea de atender al paciente que ahora, a diferencia de antes, puede recibir el cuidado especializado que necesita. Dado esos sentimientos de traición es común ver aversiones a la intervención terapéutica y son muy probables el rechazo o los intentos de fuga luego de que la persona voluntaria o involuntariamente ha decidido ingresar en una unidad psiquiátrica. En todo caso, como afirma E. Goffman ,la hospitalización confirma mediante la situación objetiva, lo que hasta entonces solo era una sospecha de la experiencia sensorial y personal del individuo (2001, 138).

Él duró creo que como dos meses. Porque la última vez que él se voló llamó a mis primos, porque él les dijo que quería ir. Lo llevaron, lo instalaron y bueno. Luego se voló y llamaba a insultar a mis primos.

Gloria V., 23 años. Hermana. 
De esta etapa de sospecha a la internación definitiva en un servicio hospitalario para enfermos mentales, podría decirse que ocurren los cambios más significativos del destino social de los individuos. El tratamiento ambulatorio resulta pertinente para algunos de los casos más moderados, sin embargo aquellas personas cuyas transgresiones al orden familiar y social han sido más graves deberán afrontar la posibilidad de tener que permanecer por lo menos durante unos días en alguna unidad psiquiátrica, al menos hasta que se muestre estable o se adhiera efectivamente al tratamiento médico. Hasta ahora, las demarcaciones de la etapa prepaciente y paciente parecen ser poco claras, pero la hospitalización es el punto en el que una persona se convierte en paciente mental. Los retos de ahí en adelante serán el de acostumbrarse a la vida y las relaciones sociales dentro de una institución para pacientes mentales.

\section{ETAPA DE PACIENTE MENTAL}

Lo que corresponde a la etapa de paciente en este texto se circunscribe a algunas apreciaciones que desde la perspectiva familiar y experta se hacen al respecto de dicho estadio. La dificultad para acceder y realizar trabajo de campo dentro de las unidades hospitalarias para enfermos mentales, ocasiona que el desarrollo sobre esta etapa de la carrera del paciente mental tenga una menor riqueza y rigurosidad comparada con las otras etapas. De cualquier forma, tampoco hacía parte de los objetivos de la investigación en una exploración de este tipo. Lo que conocemos sobre esta etapa proviene del relato familiar y de los registros médicos de las historias clínicas de los pacientes mentales con que contamos. Por ello, muchos aspectos que tienen que ver con la interacción, los procesos de definición de la identidad de los pacientes dentro de las salas, así como la organización y la vida social dentro de los hospitales psiquiátricos no se podrán abordar. No obstante, existen situaciones interesantes acerca de la interacción del paciente mental que se mostrarán en lo siguiente.

Hay que volver sobre el carácter voluntario e involuntario de la hospitalización. Al parecer son dos las motivaciones por las cuales una persona se interna voluntariamente en un hospital psiquiátrico. En primer lugar, porque cree perder la razón y el buen juicio, ve en el tratamiento médico una ayuda, para el paciente la hospitalización parece conveniente. Otras veces, el motivo proviene del exterior cuando la persona a pesar de no estar de acuerdo con la hospitalización, es persuadida por su familia para que ingrese a un servicio hospitalario para enfermos mentales. 
En contraste, están aquellas personas que son hospitalizados en contra de su voluntad, ya sea por la intervención de algún tipo de autoridad o porque son llevados bajo los engaños de sus allegados. Una vez adentro de los servicios hospitalarios de psiquiatría, los ingresados experimentarán las mismas condiciones y la diferencia entre ingresos voluntarios e involuntarios se desvanecerá.

... el día que fueron por él lo tuvieron que dopar. La esposa en ese tiempo fue la que le llevó jugo y todo eso, eso se lo prepararon en un jugo de lulo y le echaron la pastica y se la dieron y lo doparon para llevarlo y volvió y se les voló, ya luego él dijo que él quería ir. Gloria V., 23 años. Hermana.

Ellos necesitaban de la fuerza porque él no se dejaba, él no se dejaba coger, él decía que no era un delincuente que porque lo iban a llevar y él me decía que él no había hecho nada, que no lo hiciera llevar así.

Gertrudis L., 42 años. Hermana.

Llama la atención que cuando la persona ha sido ingresada a una unidad psiquiátrica por primera vez, trata de evitar que quienes lo rodean conozcan su nueva situación. Esta pretensión cubre tanto a las personas del exterior, es decir sus familiares y amigos (allegados), como al personal y compañeros de sala en la que se le haya asignado un lugar. Durante los primeros días del internamiento tratará de evitar al máximo cualquier tipo de interacción o de relación recíproca con el resto de pacientes, o por lo menos evitar que estos conozcan la vergüenza del comportamiento y las trasgresiones de las que se le acusa y que lo condujeron a la hospitalización (Goffman, 2001, p. 150).

Con frecuencia la persona evade toda conversación, posiblemente se tornará huraño para evitar cualquier relación que suponga algún tipo de aceptación de su nueva situación. El mantenerse ajeno a toda interacción con el resto de pacientes y con las empresas de los terapeutas, podrían explicarse de esa forma, pues interactuar significaría aceptar. Las siguientes son observaciones hechas por el personal médico del hospital psiquiátrico, en referencia a los primeros días de hospitalización de un paciente mental;

\section{Historia Clínica - Nota de enfermería:}

“Pte ${ }^{3}$ que permanece aislado - es necesario insistirle para el diálogo pero cuando se habla largo rato con él se va tornando hostil".

\footnotetext{
${ }^{3}$ Abreviatura de paciente.
} 
Historia Clínica - Perfil del paciente en terapia ocupacional, 24 de febrero de 1986:

“El día viernes se presenta a tto ${ }^{4}$ pero no hizo recreación. Pte con ideas delirantes a veces se torna hostil, realiza actividades pero sencillas."

En ocasiones, cuando el familiar o un allegado visita al paciente probablemente deba afrontar el rechazo. Es factible que persista en el paciente mental un sentimiento de traición hacia su familia, que se fecundó durante los momentos cúspides de la etapa pre-paciente. La hermana de un paciente mental relata la situación a la que se enfrentó durante sus primeras visitas a su hermano hospitalizado.

... a la segunda semana él todavía estaba muy mal. Incluso un día yo fui y a mí me prohibieron la ida porque él tuvo una crisis y él se puso horrible ese día y los psiquiatras lo tuvieron que aislar, o sea, dijeron que no que lo metiera a la pieza porque estaba muy alterado, porque ese día él me acusaba que yo había vendido la casa.

Gloria V., 23 años. Hermana.

Durante la hospitalización, las personas internadas cuentan historias sobre lo que les sucedió, sin embargo estos relatos no encuentran mucho eco con los demás pacientes mentales. Donde estos relatos son significativos es en la representación médica de la enfermedad mental, ya que para el personal hospitalario estas historias son síntomas indiscutibles de la perturbación del individuo. Algunos pacientes por su parte, construyen historias que tienen una versión de su identidad y rol. Recurren a veces a exagerar su estatus económico u ocupacional, pero el contexto los desacredita y el simple hecho de encontrarse en un hospital psiquiátrico deja sin fundamento los deseos de reconocimiento de los nuevos pacientes mentales.

En el registro de la historia clínica de un paciente, quien aseguraba estar internado a razón de un complot familiar, se evidencia un poco lo argumentado;

\section{Historia clínica y evolución:}

"Paciente alerta, consciente, con afecto exaltado, hiperkinético. Presenta delirios persecutorios: "Mi vecino le quiere quitar la casa a mi mamá", "mis vecinos y mi hermana llamaron a la policía para hacer que me diera un papel que dijera que estoy loco y quitarnos la

\footnotetext{
${ }^{4}$ Abreviatura de tratamiento.
} 
casa"; delirios de grandeza: "lo que pasa es que tengo mucha plata y por eso me tienen aquí". Tono de voz aumentado, producción ideoverbal aumentada. No presenta alucinaciones en el momento, no refiere ideación suicida u homicida. Orientado en 3 esferas. Igual manejo." 5

Por otra parte cuando es momento del alta, el paciente mental necesita actuar y corresponder al rol hacia el cual se le ha empujado. Su conducta debe corresponder con la de una persona dispuesta a aceptar su condición y dispuesta sobre todo a recibir ayuda. Para poderse retirar del hospital, el paciente necesita ser confiado a la supervisión y autoridad de su persona más allegada o de una autoridad del circuito mediador en caso de que el paciente se encuentre solo. Deberá permanecer bajo la vigilancia y cuidado del designado, el cual en condiciones normales carecería de este tipo de responsabilidad y poder. Con frecuencia al principio esta persona percibe un sentimiento de resentimiento por parte del paciente mental. "Cuando recién le dieron salida de San Isidro él casi no me hablaba y me miraba mal, así estuvo un buen tiempo hasta que le pasó" Rosario D., 48 años. Sobrina.

A modo de reflexión sobre esta etapa, Becker (2009) nos habla de que la formación de identidad pareciera no ser propiedad y disposición de la persona a quien se atribuye dicha cualidad, sino inherente más bien a una pauta de control social cultivada sobre esa persona, por ella misma y por cuantos la rodean y definen. El proceso de hospitalización, aparte de sus cualidades y fines terapéuticos, trae consigo un proceso de redefinición de la identidad de quienes son objeto de su intervención. Así pues, la definición del paciente mental depende tanto de sus rasgos mórbidos como de las medidas (en este caso terapéuticas y de control social)que los otros en contraposición "sanos" toman con respecto de este, alterando la percepción de identidad y rol social de la persona que ha sido objeto de intervención (Becker H., 2009, p. 25).

\section{ETAPA POST - PACIENTE Y RECIDIVA}

En esta fase de la "carrera del paciente mental" es conveniente desarrollar y contrastar dos nociones sociológicas que hacen parte de la vida social de los pacientes mentales, luego de que estos abandonan los servicios hospitalarios para enfermos mentales.

El primer punto que se desea tratar tiene que ver con la identidad y los roles de una persona, luego de que cumple con los estadios de una

\footnotetext{
${ }^{5}$ Transcrito del original.
} 
"carrera de paciente mental". Para ello, debemos partir del presupuesto teórico de que las identidades no son estables, pero se las puede hacer parecer permanentes. Una persona que fue paciente de los servicios de hospitalización psiquiátrica deberá afrontar las dificultades y presiones sociales que ejerce la etiqueta de haber estado en dicho lugar. Lo valioso de esta etapa son los ajustes que toma el entorno social frente a un atributo no deseado de la persona en cuestión, su enfermedad.

La oportunidad de construir o reconstruir un proyecto de vida sostenible parecido al que se tenía antes de la hospitalización es escasa. Se dice que la enfermedad mental y en especial la esquizofrenia no tienen cura, lo que ocasiona que la persona afectada, en teoría, no pueda volver a constituirse completamente dentro de la regularidad de su vida anterior. Con ello no se intenta decir que es imposible reestructurar la vida luego de la hospitalización, hay muchos casos en los que las personas logran dar continuidad a su vida, de alguna forma u otra se realizarán arreglos y acomodamientos que permitan continuar la vida social. Las personas tienden a reestructurar su vida, pero a costa de cambios significativos. Algunos de estos cambios se dan en la percepción de la identidad, en las relaciones sociales y en los roles desempeñados por el ahora ex-paciente. Algunos cambios son permanentes y totalmente evidentes para su entorno. La vida puede seguir, pero estos ajustes y cambios, ocasionan ruidos en las interacciones y relaciones sociales de los grupos de los que participa el expaciente como la familia.

No, él no pudo volver a trabajar porque los médicos, con el problema que él tuvo mental, los médicos ya decían que no, que él no podía trabajar, porque él tenía episodios de esquizofrenia muy seguidos, decía que escuchaba voces y que los jefes, los compañeros, le querían hacer daño. Ya no pudo trabajar pero sin embargo siguió preocupado por mi mamá, siguió preocupado porque si se pagaban los recibos, por si había comida, todo eso lo mantenía preocupado.

Gertrudis L., 42 años. Hermana.

Una segunda noción que deseamos revisar con respecto a la fase de post-paciente es la tiene que ver con el concepto de "estigma" (Goffman, 2006, p. 11). Uno de los rasgos rastreables en las interacciones entre personas normales y estigmatizadas, en nuestro caso entre personas "sanas" y los pacientes mentales, es que estas tratan de evitarse. La interacción con personas fuera de los circuitos de agencias tiende a ser una relación muy escasa y cuando se presenta. Hay de manifiesto un trato condescendiente hacia el paciente mental:"Habla con la gente a veces y pues la gente le pone cuidado pero saben que él tiene su problema y le siguen la corriente" Rosario D., 
48 años. Sobrina.

También se encontrarán casos en los que el ex-paciente tenga largos periodos de estabilidad y de lucidez, en los cuales sea capaz de relacionarse con personas fuera de sus círculos más cercanos (ex compañeros de trabajo, vecinos, empleados públicos, etc.); sin embargo, la mayoría de estas relaciones y encuentros son superfluos e intrascendentes. Las personas que cargan con el estigma y la etiqueta de haber estado en un hospital para enfermos mentales son alejados de las relaciones más serias, tímidamente se les cree incompetentes para establecer relaciones sociales complejas como el matrimonio, una actividad comercial mayor o incluso la paternidad. Todo esto no por comprobación, sino por suposición, porque se asume que una persona que estuvo en un hospital psiquiátrico no es apta para dichos compromisos.

En un informe especial sobre salud mental, la revista colombiana Semana plasma la experiencia de la estigmatización de una persona a quien se le diagnosticó un trastorno mental:

Al principio no podía concentrarme. Estaba cansado y triste, tampoco dormía bien y lloraba con frecuencia. Al caminar me sentía agobiado. Entonces le comenté a una colega y ella me recomendó que fuera al psicólogo. Le hice caso y ante una crisis grave, me remitieron al psiquiatra. Con él llegamos a la conclusión de que padecía depresión severa. Alcancé a pensar en suicidarme, pero con medicamentos y terapia empecé a mejorar. Lo más cruel, sin embargo, es que mis compañeros de trabajo me aislaron, incluida la amiga que me sugirió buscar ayuda. Como mi rendimiento decayó, se empeñaron en sacarme porque para ellos yo era indeseable. No se fijaron en mi trayectoria ni me dieron la oportunidad de recuperarme. Me sentí abusado, rechazado y excluido. Parecía que un monstruo me estaba aplastando. Al final, en una jugada calculada, se deshicieron de mí y me mandaron a otra ciudad. Fue un dolor muy profundo, pero sobreviví y salí fortalecido. (Revista Semana, 2013)

Particularmente el paciente con esquizofrenia que no se adhiere al tratamiento médico, o por lo menos el farmacológico, tiende a aislarse socialmente, no está claro si como producto de la enfermedad o más bien por la respuesta de sus círculos cercanos ante lo que ellos perciben como un comportamiento irascible. Esta condición lleva a que el post-paciente mental estigmatizado asuma (no siempre) una conducta depresiva, hostil, desconfiada, aturdida o por lo menos ansiosa. La precariedad de intercambio social y la combinación de su situación mórbida con otras formas de desviación terminan por resaltar el estigma y aislar al individuo. 
El quedó solo en la casa. Y él empezó a desbaratar la casa, empezó a arrancar las baldosas y a venderlas para él consumir. Empezó a arrancar las puertas, toda la casa de él quedó en obra negra totalmente. Porque toda la desbarató. Parecía un indigente, no sé si se diga así, pero él no se bañaba nada nada, era algo muy triste verlo así. Gloria V., 23 años. Hermana.

Separar la personalidad de la enfermedad es una tarea cotidiana que obliga al post-paciente a actuar siempre con reservas, ya que una impropiedad accidental o un yerro pueden ser considerados como una expresión directa de su calidad de enfermo mental. En estas circunstancias, las opciones del individuo estigmatizado pueden ser dos: el retraimiento o el enfrentamiento, con las cuales también se corre el riesgo de que sean tomadas por su entorno como una prueba más de su condición. Así pues, las reacciones normales de un individuo sometido a presiones, ante los ojos de otro se convierten en transgresiones y evidencias que justifican todo cuando se hizo y cuanto debería hacerse con el paciente mental.

Luego, en la etapa post-paciente es común que los "circuitos allegados" sean testigos de las medidas que la sociedad toma frente al paciente mental, y deben en muchas ocasiones, compartir el descrédito de una persona estigmatizada con quien se comparte una relación íntima. A menudo, la familia opta por una actitud corajuda y solidaria con sus seres queridos disminuidos por el tratamiento social.

Cuando son bautizos, matrimonios y cosas así de la familia y solo invitan a mi mamá, ella no va que porque ella dice que porque solo invitaron a uno sabiendo que ellos son tres. Y si va, se viene rápido diciendo que los muchachos quedaron solos.

Gertrudis L., 42 años. Hermana.

Ahora bien, sabemos que quienes fueron en algún tiempo paciente mentales tienden a tener menor entusiasmo de conformar fraternidades entre sus ex compañeros o individuos en similar condición. En los ex presidiarios y los enfermos mentales es poco común ver re-encuentros o reuniones entre los ex internos, a nadie le conviene que los demás sepan que fueron presidiarios o que estuvieron en un "manicomio", no hay razón para jactarse de un episodio así. Con frecuencia, quienes representan a estos grupos son organizaciones compuestas por familiares o personas que pertenecen al grupo de los otros "normales" y "sanos". Por ejemplo, en Colombia existe la Asociación Colombiana de Personas con Esquizofrenia y Familias (ACPEF), una entidad privada sin ánimo de lucro, impulsada inicialmente por grupos familiares de personas con 
esquizofrenia y especialistas en el área, con el fin de ayudarse mutuamente en el tratamiento y manejo de la enfermedad. Hoy en día, la asociación tiene más de una década desde su apertura y acoge a una gran cantidad de familias y pacientes; sin embargo, sus voceros principales, representantes y dirigentes no son los propios pacientes mentales.

\section{CONCLUSIONES}

La discusión sobre el alcance conceptual y empírico de la noción de "carrera del paciente mental" es un trabajo que aún debe desarrollarse. No está bien sacar conclusiones teniendo como base solo la aproximación anteriormente expuesta. Sin embargo, existen varios hechos de interés sobre los cuales hay que hacer mención. El primero de ellos es que hoy nos encontramos con una disciplina psiquiátrica reflexiva, mucho más enfocada en la prevención y en la promoción de la salud mental que en el tratamiento farmacológico y clínico de la enfermedad mental. El cuidado de la salud mental consiste en evitar los factores de riesgo y generar hábitos saludables. El internamiento ya no es la medida terapéutica principal para tratar la enfermedad mental, pero aún se mantienen los servicios hospitalarios para enfermos mentales. Eso sí, con una reducción sustantiva en los tiempos de internamiento de los pacientes mentales y las condiciones del mismo.

En segundo lugar, todavía existe una imagen "naturalista" extendida de la enfermedad mental. Lo que se intentó en este trabajo era mostrarle al lector un proceso social común entre quienes comparten la experiencia de padecer y relacionarse con la enfermedad mental. Creemos que la enfermedad mental como concepto debe ser heterogéneo e interdisciplinar, por lo tanto no existe factor social transformador totalizante en la trayectoria del paciente mental.

Por otra parte, el concepto de enfermedad mental en la familia se modifica por el conjunto de posibilidades que brinda el discurso médico en las etapas avanzadas de la carrera, de las cuales carecía la familia al inicio de la carrera. Sin embargo, la familia no se limita a actuar conforme a un marco de referencia racional, sino que puede generar sus propias versiones acerca de la realidad y los procesos de enfermedad. La familia debe ser tomada como un conjunto dinámico capaz de hacer cosas, no un sujeto pasivo en el proceso de elaboración del paciente mental.

Desde el punto de vista de su rol como parte del circuito de agentes y agencias que intervienen en la construcción del paciente mental, la familia no puede definir por sí sola la enfermedad y por tanto la suerte de un paciente mental. Igualmente, es muy poco probable que las "agencias 
mediadoras" como los psiquiatras puedan hacerlo de forma independiente de las otras agencias y agentes. Un aspecto que nos parece notable para la consolidación de un individuo como paciente mental es la hospitalización, la cual depende en gran medida de las contingencias que la dinamizan. Allí, ni la familia ni los expertos ni ninguna otra agencia por sí sola, permiten prever si una persona va a dar el paso definitivo hacia su elaboración como paciente mental.

Así pues, no basta con que la familia crea que a su pariente lo está aquejando la locura, se necesita que la persona cumpla con la expectativa de enfermedad mental de los expertos y que las condiciones sociales sean favorables a la hospitalización psiquiátrica. Por tal razón, la definición de quién es un enfermo mental y cuándo una persona necesita ser hospitalizada, no puede depender de un solo agente. La caricatura de la familia como ente conspirador en contra del individuo alienado carece de fundamento, por lo menos en el tipo de explicación del proceso que aquí se formula. Además, es claro que hoy los procesos de internamiento no corresponden ni exclusiva, ni enteramente, a situaciones puramente de demandas de control y poder social.

Repetimos, en la actualidad nos encontramos con un escenario en que los servicios médicos de psiquiatría abogan por reducir los tiempos de internamiento del paciente en los servicios psiquiátricos (tanto por las condiciones económicas del servicio como por los nuevos horizontes terapéuticos de la disciplina). De manera similar, existe la voluntad de evitar al máximo la hospitalización psiquiátrica de las personas, a menos que sea estrictamente necesaria; en cambio ha habido una tendencia por aumentar los esfuerzos en una línea más preventiva de salud mental.

En cuanto a los síntomas, más allá de la discusión sobre su naturaleza, de si se pueden denominar como síntomas de una enfermedad en los términos psicofisiológicos o no, debemos indicar que la presencia de alteraciones en la conducta normal habitual de las personas que han sido diagnosticadas con alguna de las formas de esquizofrenia, es por mucho evidente. Inclusive la observación esporádica y arbitraria de situaciones cotidianas de los pacientes mentales en sus hogares, deja en evidencia algunos síntomas y signos de sufrimiento psíquico.

Las percepciones familiares de los síntomas y de la enfermedad en general varían en función del rol y la distancia social; por ejemplo, los padres del paciente mental pueden dar cuenta de la evolución de los síntomas a través de la carrera del paciente de una forma más detallada que un sobrino o el hermano menor del paciente. El cónyuge de un paciente mental podría aportar un relato más nutrido que los de la familia de origen, por ejemplo.

También es importante precisar que lo que nos ofrecen los familiares 
son apreciaciones de acontecimientos que a menudo desbordan su comprensión y que por tanto, en su origen no son signos, sino descripciones de anormalidad y desviación. Por último, recalcar que la función de la definición médica de enfermedad mental en el grupo familiar no es propiamente la de ayudar a entender el proceso de enfermedad, sino aportar una explicación y un proceso que dé continuidad a la vida social de la familia y del paciente. La previsión de un curso normal de la enfermedad proporciona un sustento racional, un marco de referencia a la familia para que adecue la forma de proceder ante los acontecimientos.

\section{BIBLIOGRAFÍA}

Becker, H. S. (2009). Outsiders: hacia una sociología de la desviación. Madrid: Siglo Veintiuno.

Goffman, E. (2001). Internados: la situación social de los pacientes mentales. Buenos Aires: Amorrortu Editores.

Goffman, E. (2006). Estigma. Buenos Aires: Amorrortu Editores.

Moreno Pestaña, J.L. (1999).Contingencia de carrera y enfermedad mental: Razonamiento sociológico y problemas filosóficos. En: Aproximaciones a la contingencia; historia y actualidad de una idea (Vol. 34). CYAN.

Grupo de salud mental de la Secretaría de Salud Departamental y Grupo de Vigilancia Epidemiológica (2010). Perfil de algunos eventos relacionados con la salud mental en el Valle del Cauca. Gobernación del Valle del Cauca.

Tizón, J. L., Artigue, J., Parra, B., Gomá, M., Ferrando, J., Pareja, F., \& Parés, A. (2004). La esquizofrenia en atención primaria: el estudio SASPE (señales de alerta y síntomas prodrómicos de la esquizofrenia en atención primaria). En: Atención primaria, 34(9), 493498.

Usall, J. (2003). Diferencias de género en la esquizofrenia. En: Rev. Psiquiatría FacMedBarna, 30(5), 276-87.

Revista Semana. (2013). Atrapados con salida. Informe Especial. Mayo 25 de 2013. Consulta en línea: 10 de diciembre de 2013, 19:00 horas. http://www.semana.com/vida-moderna/ articulo/atrapados-salida/344293-3

Ruiloba, J. V. (2003). Concepto de enfermedad mental. Medicine, 8 (104), 5585-5589. 